\title{
A alfabetização no Mobral, métodos e materiais didáticos (Uberlândia/MG, 1970-1985)
}

\author{
Literacy in Mobral, methods and materials \\ (Uberlândia/MG, 1970-1985)
}

\section{La littératie au Mobral, les méthodes et les matériaux (Uberlândia/MG, 1970-1985)}

Letícia Borges de OLIVEIRA

Sauloéber Társio de SOUZA

\begin{abstract}
RESUMO
Este artigo apresenta parte da análise estabelecida na dissertação de mestrado realizada nos anos de 2009 e 2010. Estudo que investiggu o processo de implantação e desenvolvimento do Movimento Brasileiro de Alfabetização (Mobral) na zona rural do município de Uberlândia//MG (1970-1985). Nesse percurso, recorremos à pesquisa bibliográfica, bem como a pesquisa documental no acervo do Arquivo Público Municipal. Foram localizados e analisados parte do material didático utilizado nas salas de alfabetização do Mobral no meio rural, que foram cuidadosamente guardados por alguns ex-alunos e ex-professoras. Neste artigo, apresentamos a análise realizada das Cartilhas do Mobral utilizadas no cotidiano da prática das professoras do campo. Além disso, identificamos a ideia antagônica entre campo e cidade no material didático.
\end{abstract}

Palavras-chave: Educação no campo; Mobral; analfabetismo; Educação de Jovens e Adultos.

\begin{abstract}
This paper presents part of the analysis of a master's thesis completed in 2009 and 2010, which investigated the process of implementation and development of the Brazilian Literacy Movement (Mobral) in rural Uberlândia/MG (1970-1985). We turned to literature reviews as well as documentary research found in municipal public archives. A portion of the Mobral literacy teaching material used in rural classrooms were located and analyzed, which had been carefully stored by former students and teachers. This article presents an analysis of the Mobral
\end{abstract}


primers (workbooks) used daily by rural teachers. In addition, we identified the antagonistic idea between country and city in the educational materials.

Index terms: rural education; Mobral; illiteracy; Youth and Adult Education.

\section{RÉSUMÉ}

Ce document présente une partie de l'analyse établie dans la thèse de maîtrise tenue dans les années 2009 et 2010. Cette étude a enquêté sur le processus de mise en œuvre et le développement du Mouvement brésilien d'alphabétisation (Mobral) dans les régions rurales d'Uberlândia / MG (1970-1985). Dans ce contexte, nous nous sommes tournés vers la littérature ainsi que vers la recherche documentaire dans la collection des Archives municipales publiques. Une partie du matériel pédagogique a été localisée, analysée et utilisée dans les cours d'alphabétisation du Mobral des zones rurales, qui ont été soigneusement gardées par quelques anciens élèvés et anciens enseignants. Cet article présente l'analyse des "Cartilhas do Mobral» utilisées dans la pratique quotidienne des enseignants dans le champs, en plus, nous avons identifié la relation antagoniste entre lá zone rurale et la ville dans les matériaux didatiques.

Mots-clés: éducation rurale; Mobral; analphabétisme; Education de jeunes et d'Adultes.

\section{Introdução}

O presente artigo apresenta resultados parciais da dissertação de mestrado "Educação no campo: Mobral no meio rural de Uberlândia/MG (1970-1985)". Esta pesquisa analisou parte do material didático utilizado pelo Mobral (Movimento Brasileiro de Alfabetização), bem como a metodologia utilizada nas praticas pedagógicas das salas de alfabetização instaladas na zona rural do município de Uberlândia/MG.

Com objetivo de melhor compreender o percurso histórico de exclusão de grande parte da população ao acesso à educação formal, assim como a criação de campanhas as quais objetivavam reduzir os índices de 
analfabetismo entre a população jovem e adulta do Brasil, também recorremos ao estudo dos referenciais teóricos sobre o tema.

Nesse processo, identificou-se que a educação de adultos surgiu no Brasil associada à educação elementar comum. Somente após a Revolução de 1930, foram estabelecidas as primeiras iniciativas significativas direcionadas a esse tipo de ensino (PAIVA, 1987). A expansão da educação de adultos foi intensificada após a $1^{\text {a }}$ Guerra Mundial, a partir das atividades de educação popular que, em sua concepção, englobaria a Educação de Jovens e Adultos (EJA).

Com a redemocratização em 1945, teve inicio a mobilização em torno do problema da educação de adultos. Mais do que o ensino supletivo, era necessário atuar maciçamente junto aos jovens e adultos analfabetos, pois se tratava da camada da população em idade produtiva (de 15 a 35 anos), objetivo que se vinculava diretamente aos ideais da demôcracia liberal do pós-guerra.

Nesse contexto, a partir da regulamentação do Fundo Nacional de Desenvolvimento da Educação (FNEP), em agosto de 1945, foi promovida uma difusão do ensino elementar, principalmente o primário. Contudo, essa expansão se efetivou de forma precária. Como a oferta de vagas permanecia insuficiente, isto contribuiu para o crescente índice de analfabetismo no país, de forma que, na segunda metade do século $\mathrm{XX}$, a população estava em 51 milhões, 944 mil e 397 habitantes, e o índice de analfabetismo era de $50 \%$ entre as pessoas maiores de quinze anos. Naquele período, 360 municípios brasileiros não contavam com qualquer prédio escolar, e os existentes nos demais municípios apresentavam instalações extremamente precárias, principalmente os da zona rural (PAIVA, 1987). Lembremos que em $1950,63,84 \%^{1}$ da população viviam no campo.

\footnotetext{
${ }^{1}$ IBGE, Censo Demográfico 1940/2000. Dados extraídos de: Estatísticas do século XX. Rio de Janeiro: IBGE, 2007. Diversas tabelas.
} 
Nesse cenário, evidencia-se que, com a aceleração do processo de urbanização, o ensino rural foi preterido em relação ao ensino urbano, aumentando a necessidade de se oferecer mais vagas nas escolas das cidades, com intuito de atender às demandas do aumento populacional dos centros urbanos provocada pelo êxodo do campo.

Como forma de amenizar essa situação, foi aprovada a primeira grande campanha ${ }^{2}$ de educação, no final da década de 1940, dirigida predominantemente ao meio rural, a Campanha de Educação de Adolescentes e Adultos (CEAA). Tal campanha teve início em 1947 e se estendeu até 1963. A CEAA contava com recursos provenientes de organizações públicas e particulares. Buscava-se articular estratégias para mobilizar os diversos setores da sociedade brasileira em prol da causa comum de acabar com o analfabetismo no Brasil. Nessa lógica, tentava-se associar o objetivo da campanha à transformação social e ao desenvolvimento do país (FREITAS, 2009, p. 213).

Posteriormente, a CEAA partiu para as missões rurais no interior do Brasil com a proposta de incentivar a modernização no campo, contudo, não pretendia modificar o equilíbrio das forças políticas locais. Além da alfabetização, havia a preocupação de incentivar a organização comunitária no campo. Por outro lado, a partir de ações extensivas, o programa priorizou o aspecto quantitativo em detrimento ao qualitativo.

A partir dessa campanha, Getúlio Vargas explicitava seu intuito de conter a migração rural demonstrando o claro apoio às Oligarquias Rurais. Tratou-se da primeira experiência a colocar essa orientação em prática numa larga escala, porém, com a preocupação de se manter o equilíbrio eleitoral no interior do país. No entanto, a pouca adequação do ensino às condições da vida rural foi um dos fatores que contribuíram para o fim da campanha, à

\footnotetext{
${ }^{2}$ É importante destacar que, em 1930, foram implantadas campanhas que atenderam os moradores do meio rural, tal como a Cruzada Nacional pela Educação (CNE) de 1932 (FREITAS, 2009).
} 
medida que a CEAA adotava uniformidade metodológica como orientação para todo país, sendo igualmente empregados no meio urbano e rural.

Em 1952, para atender a educação rural, foi criada a Campanha Nacional de Educação Rural (CNER), tendo como principal instrumento as missões rurais. A campanha indicava o princípio da organização social das comunidades, com objetivo de estimular a entreajuda da população da zona rural, na busca de solução de problemas locais, bem como a consolidação do trabalho no campo. Para tanto, organizaram-se os Centros Sociais de Comunidade que, dentre as atividades desenvolvidas, promovia a formação de professores leigos.

Eram evidentes as proposições ideológicas do programa, tal como o localismo (a supervalorização dos fenômenos locais). A campanha empregou esforços para a fixação do homem no campo, contudo, eles não foram suficientes para evitar o êxodo rural da década de 1950.

Desse modo, na busca por uma "vida melhor", o processo de migração do campo para os centros urbanos se intensificou na segunda metade do século XX. O morador do campo procurava encontrar melhores condições de trabalho na cidade.

Os resultados da CNER não foram muito expressivos, não obstante, sua influência se fez de forma marcante. A campanha enfatizava a crença na educação para a promoção de desenvolvimento. Acreditava-se que a educação poderia modificar profundamente a realidade da população, independentemente da real condição econômica das comunidades (PAIVA, 1987).

Entre 1955 e 1961, com a política desenvolvimentista do governo de Juscelino Kubitschek, as campanhas tradicionais de educação de adultos se apresentaram inadequadas à nova conjuntura, em função da pouca eficiência na formação de mão de obra para a indústria. Ressalta-se que as campanhas de alfabetização de adultos praticamente desapareceram nesse período. Desse modo, em 1958, o presidente Juscelino Kubitschek convocou um 
Congresso de Educação de Adultos, no entanto, o evento acabou por priorizar os debates acerca da educação primária (FREITAS, 2009).

No início da década de 1960, como consequência dos movimentos de educação de adultos realizados nos períodos anteriores, constatou-se o aumento do eleitorado, apresentando o crescimento de quase $50 \%$ entre 1950 e 1960 (7,9 milhões em 1950 e 11,7 milhões em 1960). No governo João Goulart, a educação das massas ganhou atenção. Surgiram diversas propostas oficiais para educação de adultos, o que representava a tentativa de centralizar a coordenação dos programas, como forma de recomposição do poder político.

Nesse cenário, movimentos sociais de esquerda e setores da Igreja Católica buscavam mudanças na realidade brasileira a partir da identificação dos problemas internos, com o objetivo de promover a conscientização política das camadas populares e ampliar a participação popular, dando ênfase na valorização da cultura nacional. Na primeira metade da década de 1960, nascem iniciativas como os Movimentos de Cultura Popular (MCP) e os Centros Populares de Cultura (CPC), os quais tinham a pretensão de ampliar a participação política, além de:

[...] a) promover e incentivar, com a ajuda de particulares e do poder públieo, a educação de crianças e adúltos; b) atender ao objetivo fundamental da educação que é o de desenvolver plenamente todas as virtualidades do ser humano, através da educação integral de base comunitária, que a assegure, também, de acordo com a Constituição, o ensino religioso facultativo; c) proporcionar a elevação do nível cultural do povo, preparando-o para a vida e para o trabalho; d) colaborar para a melhoria do nível material do povo, através da educação especializada; e) formar quadros destinados a interpretar, sistematizar e transmitir os múltiplos aspectos da cultura popular (CUNHA, GÓES, 1989, p.17).

Considera-se que o período entre o final da década de 1950 e início de 1960 foi muito produtivo no que se refere às experiências da educação popular. Em especial, as realizadas na região Nordeste do país, que projetou 
Paulo Freire com um Sistema de Alfabetização no contexto do MCP (FREITAS, 2009, p. 233-234).

Ligado à Conferência Nacional dos Bispos do Brasil (CNBB), o MCP pretendia oferecer à população rural oportunidade da alfabetização num contexto mais amplo, buscando a promoção do homem do campo, além de ofertar-lhe a formação cristã, tornando-o consciente de seus valores físicos, espirituais, morais e cívicos. Já os CPC iniciaram suas atividades entre 1962 e início de 1964 e, a partir de sua ligação com a União Nacional dos Estudantes (UNE) e jovens intelectuais do Teatro Arena, organizaram espetáculos teatrais e produções cinematográficas na tentativa de atingir um novo público, as massas populares.

Em setembro de 1963, foi organizado o I Encontro Nacional de Alfabetização e Cultura Popular. Observou-se que o objetivo comum desses movimentos era a transformação das estruturas socioeconômicas, com a finalidade de organizar a sociedade para modificar as condições que criaram o problema do analfabetismo. Os movimentos tinham como prioridade não somente a educação dos adolescentes e adultos, mas também criticar a proibição do voto do analfabeto. Importa salientar que, nas discussõ̉es do encontro, foi reconhecida a necessidade de alcançar os analfabetos da zona rural, uma vez que naquele período, segundo o IBGE, 55,5\% da população vivia no campo. Entretanto, nenhuma ação concreta foi tirada do evento nesse sentido.

Desse modo, a partir da realização do II Congresso Nacional de Educação de Adultos enfatizou a necessidade da elaboração de novos métodos para a educação dos adultos, o que favoreceu novas possibilidades de atuação educativa, tal como o surgimento de métodos específicos para a alfabetização da população adulta. Destaca-se que as maiores contribuições para a elaboração desses métodos foram provenientes dos grupos cristãos, em especial, o movimento Teologia da Libertação. 


\section{EJA e o período pós-1964}

No ano de 1963, o Brasil foi cenário de diversas manifestações sociais que acirraram a polaridade entre os pensamentos das correntes de direita e esquerda em relação à situação política do País. A partir de 1964, agravou-se a instabilidade política e econômica, o que aumentaria a insatisfação de setores do empresariado e das classes dominantes com o governo do presidente João Goulart, o Jango.

Em março de 1964, as tensões políticas foram acirradas, o que contribuiu para a organização da conspiração militar contra o governo, desencadeando o movimento golpista. Com a tomada do poder, os militares se mobilizaram para a escolha de quem iria chefiar o novo governo, o candidato foi o general Castelo Branco.

Assim, o Brasil foi inserido num contexto de intensa repressão (especialmente nos grandes centros) e de perseguição aos líderes considerados "subversivos" que supostamente levariam o País ao comunismo. Milhares foram presos em ações como a "Operação limpeza", que perseguiu tanto membros de organizações católicas como o Movìmento de Educação de Base (MEB) ${ }^{3}$ e a Juventude Universitária Católica (JUUC). Muitos foram executados e outros sofreram torturas no interior dos quartéis do exército (SKIDMORE, 1988).

A educação de jovens e adultos, no início do governo militar, foi marcada pela falta de investimentos. Somente em 1966, diante da má repercussão internacional dos elevados índices de analfabetismo aliada aos apelos da Unesco, o governo brasileiro elaborou o Plano Complementar em trabalho conjunto entre Conselho Federal de Educação, Ministério da Educação (MEC) e Secretaria de Planejamento. Daí assumiu as diretrizes

\footnotetext{
${ }^{3}$ O MEB era um movimento ligado a Conferência Nacional dos Bispos do Brasil (CNBB), financiado pela União desde 1961. Caracterizava-se como movimento de cultura popular, com intuito de oferecer à população rural oportunidade de alfabetização em contexto mais amplo de educação de base (PAIVA, 2003).
} 
técnicas de modo a estabelecer estratégias para reduzir os índices de analfabetismo que, segundo o IBGE, em 1960 eram de 39,50 \% da população com mais de 15 anos de idade.

Com a Ditadura Militar, teve início o processo de perseguição e repressão aos programas de educação popular, que eram realizados no período anterior ao golpe. Aqueles que permaneceram praticamente ficaram relegados a um plano secundário.

Somente no final de 1966, o governo retomaria tal questão, por meio da Cruzada ABC -Ação Básica Cristã, como forma de neutralizar as ideias de esquerda difundidas nos programas anteriores. No entanto, em função de dificuldades financeiras, foi extinta em 1971. Com o fim das Cruzadas pela Alfabetização, emergiu a necessidade de se estabelecer um novo programa de educação para atender ao elevado contingente de pessoas jovens e adultas analfabetas, o que culminou no surgimento do Mobral. Ressalta-se que foi justamente naquele período que ressurgiu a ideia do analfabeto cómo "mancha negra" a ser exterminada (FERNANDES, 2002).

Em 1969, a Fundação Mobral foi criada por meio da Lei no. 5.379. O programa sucedeu a mobilização observada nos meses anteriores em relação ao problema da educação de adultos ${ }^{4}$. Porém, ele só começou a funcionar efetivamente no ano de 1970.

Lançado com ampla divulgação e mobilização pela imprensa falada e escrita, o programa objetivava atingir um grande contingente popular tendo como principal meta erradicar o analfabetismo entre pessoas jovens e adultas entre 15 a 35 anos.

\footnotetext{
${ }^{4}$ Em 8 de setembro de 1967 (Dia Internacional da Alfabetização) foram assinados vários decretos prevendo a constituição de um grupo interministerial para o estudo e levantamento de recursos destinados à alfabetização (Decreto $n^{\circ}$ 61.311), à utilização das emissoras de TV nos programas de alfabetização (Decreto $n^{\circ}$ 61.312), a constituição da Rede Nacional de Alfabetização Funcional e Educação Continuada de Adultos (Decreto $n^{\circ}$ 61.313), a educação cívica nas instituições sindicais e a campanha em prol da extinção do analfabetismo (Decreto $\mathrm{n}^{\circ}$ 61.314). Tais decretos já apontam para a ideia do novo interesse pelo problema. No DNE, continuavam a se realizar estudos e trabalhos de planejamento nessa matéria, originados do Plano Complementar (PAIVA, 1987, p. 292).
} 


\section{O Mobral em Uberlândia/MG}

O município de Uberlândia está situado no Triângulo Mineiro, região considerada uma das mais importantes do Estado de Minas Gerais, pois, dentre outros fatores, destaca-se em função de sua localização geográfica estratégica, que viabiliza o escoamento da produção de vários Estados do país.

Nesse cenário, destaca-se o expressivo desenvolvimento econômico, impulsionado também pela transferência da capital federal para Brasília, região vizinha ao município. Como reflexo, o crescimento urbano provocaria uma mudança estrutural significativa para a cidade, acirrando os problemas sociais (VIEIRA, 2000).

Apesar da ênfase ao desenvolvimento econômico do município, constata-se que na década de 1970, o índice de pessoas acima de quinze anos que não eram alfabetizadas era de $17,4 \%$. Fator que motivou a adỏção do Mobral no município, inclusive, na zona rural.

Por conseguinte, em 1971, o município de Uberlândia estabeleceú convênio com o programa, na gestão do prefeito Virgílio Galassi. Conforme mostra o Jornal Correio, em 1972, e no relato da ex-coordenadora do programa, Olga Lara Cardoso, Uberlândia foi uma das cidades pioneiras na implantação do Mobral no Estado de Minas Gerais.

\section{Material didático do Mobral}

O material didático produzido para o Mobral era distribuído gratuitamente para alunos e educadores do programa. Além da diversificação, destaca-se que o número de exemplares publicados também era expressivo. Para tanto, significativa parte dos recursos que o programa recebia foi utilizada para a produção do material didático. 
A partir da análise de alguns dados, é possível compreender a dimensão entre o volume e a distribuição do material produzido. Assim, em 1972, do total de oito milhões e 812 mil alunos escritos, sete milhões e 354 mil estavam nos cursos de alfabetização, 950 mil na Educação Integrada e 508 mil no curso de Desenvolvimento das Comunidades. Contudo, o critério que definia a tiragem e o número de exemplares que seriam distribuídos não correspondia à demanda (FREITAS, 2009, p. 254-255).

Desse modo, para os sete milhões e 354 mil alunos inscritos no curso de alfabetização, foram publicados e distribuídos quatro milhões e 844 mil livros de leitura, 12 milhões e 171 mil livros de leitura complementar e 48 milhões diários do Mobral. Identifica-se que à tiragem do livro de leitura foi abaixo do número de inscritos, por outro lado, a do livro de leitura complementar era superior à demanda da inscrição (FREITAS, 2009, p.356257).

É importante lembrar que as coleções didáticas produzidas em làrga escala não foram elaboradas pelas equipes técnicas do Mobral. A edição e impressão foram realizadas por três empresas privadas: Abril Cultural S.A., a Bloch Editores S.A. e a Gráfica Editora Primor S.A. Importa realçar que todas produziam os livros para atender aos mesmos objetivos, a alfabetização de jovens e adultos. Diante disso, identifiça-se a disputa acirrada entre grandes empresas para garantir participação no projeto que, por sua vez, garantia elevados ganhos financeiros. Esse processo também pode indicar que o Mobral atendeu aos interesses de grandes editoras (FREITAS, 2009, p.255, 256).

Importa frisar que Mobral não apresentou uma proposta específica para a educação do campo. Contudo, o ambiente rural era retratado nas cartilhas do programa. Possivelmente, isso se dava em função de que nas décadas de 1970 e 1980, segundo dados do IBGE, respectivamente 44,06\% e $32,41 \%$ da população ainda residia na zona rural e o êxodo era cada vez mais crescente. 
Por outro lado, nas ilustrações do material didático da campanha, o contexto urbano era apresentado como espaço de "oportunidades" e melhores condições de vida. Como a proposta de ensino previa a implantação de forma homogênea em todo território nacional, verifica-se a reprodução da "superioridade" do espaço urbano e a "idealização" pejorativa do campo, visto como lócus de "atraso", sendo retratado como lugar "pacato" e "tranquilo".

A perspectiva do Mobral no campo não se relacionava à contenção do êxodo rural. Com a campanha, buscou-se de alguma forma "preparar" o trabalhador para o consumo e a vida urbana, dotando-o de ferramentas mínimas, mas necessárias para a consolidação de mercados consumidore

Com princípios semelhantes aos da disciplina de Educação Moral e Cívica $^{5}$ oferecida ao ensino primário, ginasial e colegial naquele período, algumas imagens e palavras do material didático do Mobral visavam inculcar determinadas mensagens que seriam favoráveis à manutenção da “ordem”, a qual seria garantida pelo Regime Militar.

Os conteúdos do material didático enfatizavam as questões referentes à comunidade, à Nação e a consolidação de hábitos e atitudes baseados na moral cristã atribuindo valor positivo à pátria, à família e a religião.

Nessa lógica, a educação foi um veículo importante para difundir determinados valores tais como: passividade, ordem, fé, "liberdade com responsabilidade" e patriotismo. Como tentativas de homogeneizar valores e ações favoráveis ao projeto empreendido pelos segmentos sociais que

\footnotetext{
${ }^{5}$ A disciplina Educação Moral e Cívica foi instituída pelo Decreto-Lei no 869, de 12 de setembro de 1969. Os programas do ensino primário partiam daquilo que era próximo à criança, à família e à escola, para posteriormente passar ao estudo da comunidade, do País e do mundo. O conteúdo para o curso ginasial e colegial era explicitamente ideológico e manifestava a fusão do catolicismo conservador e da ditadura da segurança nacional (CUNHA; GOÉS, 1985, p. 75).
} 
governavam o país durante a Ditadura Militar (NUNES; REZENDE, 2008, p. 2, 4).

Destacava-se a ideia de "responsabilidade pessoal" dos alunos do Mobral pelo êxito ou fracasso no processo de alfabetização, além de difundir os padrões da vida moderna como a ideal. Sendo assim, percebe-se o incentivo às novas possibilidades de consumo aos alunos do programa, em especial aos trabalhadores do campo que, por sua vez, deparavam-se com a imagem da vida urbana como espaço de "progresso" e acesso às tecnologias que o mercado poderia oferecer.

Em algumas ilustrações, a cartilha do programa ilustra imagens de famílias "desfrutando" dos benefícios que o rádio e a televisão poderiam oferecer como fonte de entretenimento. Lembremos que, ainda na década de 1970, a televisão era um bem pouco difundido nas cidades, o que dizer então das zonas rurais? A ilustração a seguir, certamente, vendia o sonho da prosperidade no meio urbano.

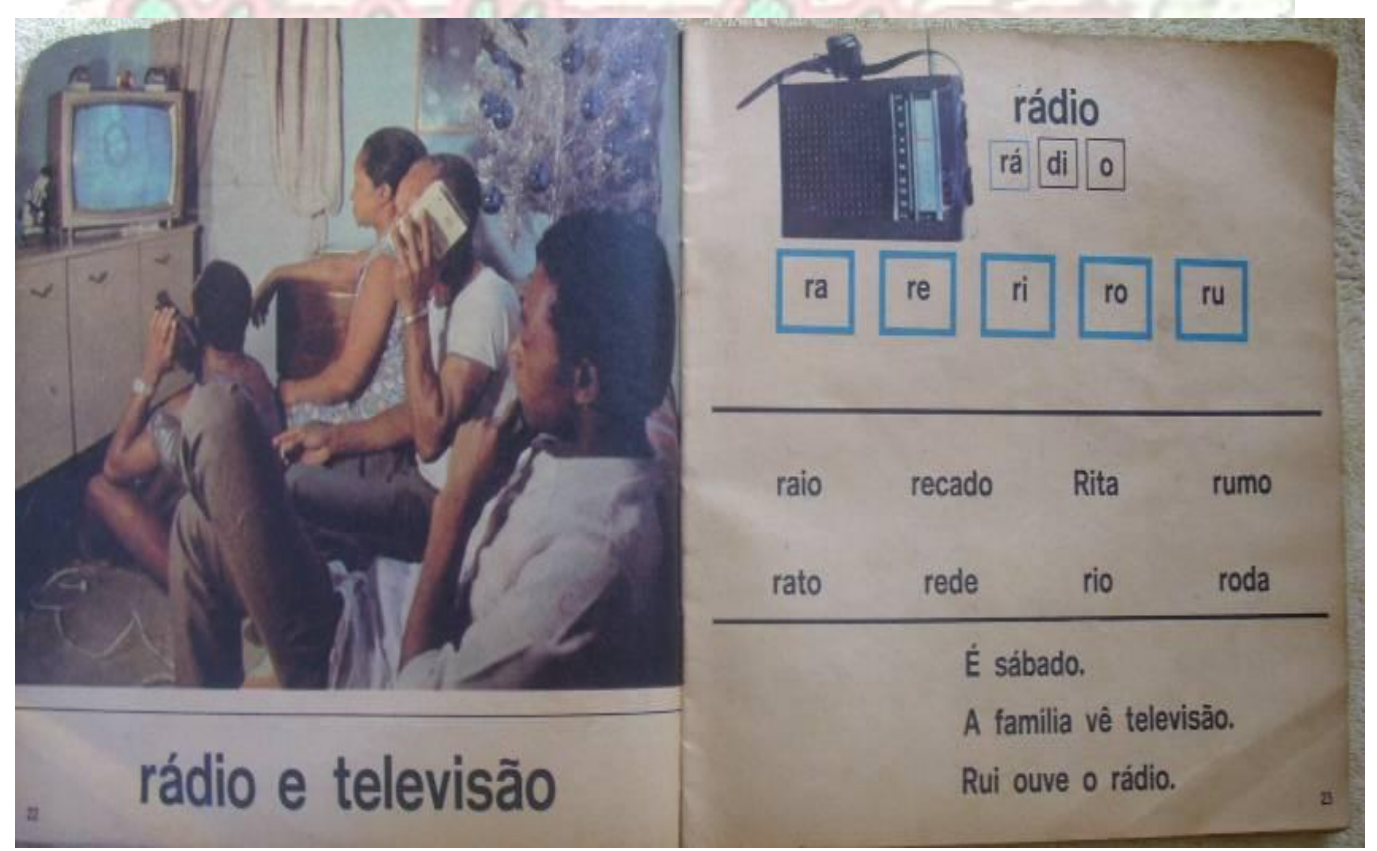

Imagem 1- Cartilha do Mobral, p.22-23, sem data. Fonte: Acervo pessoal Sebastião Araújo Sobrinho 
Constata-se que as mensagens da cartilha do programa indicavam que seria possível alcançar os "benefícios" que a tecnologia poderia proporcionar se fosse empregado o esforço individual. Nesse sentido, notase que o compromisso ideológico do Mobral se distanciava e falseava as iniciativas anteriores à Ditadura Militar, as que estimulavam a reflexão, inclusive sobre as causas do analfabetismo (FREITAS, 2009, p. 258-259).

$\mathrm{O}$ regime utilizava a educação para atingir seus objetivos e interesses, instruindo a partir da ideia de que "todos" poderiam gozar das "benesses" que o "desenvolvimento" poderia proporcionar, inibindo a construção de qualquer outra forma de organização social diferente daquela difundida pelos militares.

A Ditadura enfatizava que a "Revolução" seria a favor de toda população. Todas as ações eram colocadas como sendo a serviço do povo, tudo que o grupo dirigente realizava no interior da política, era, ségundo eles, democrático (NUNES; REZENDE, 2008, p. 4).

Assim como a família deveria determinar sobre o que seria bom ou ruim para os filhos (principalmente por intermédio da figura do pai), o\$ representantes do governo também poderiam determinar as leis que consideravam "necessárias" para o "bem” da Nação (NUNES; REZENDE, 2008, p.9).

$\mathrm{Na}$ imagem abaixo, Identificamos a representação de uma família em que a figura paterna é central, ao passo que os demais são subjugados, principalmente a mulher, que apresenta uma postura submissa e contemplativa. 




Imagem 2- Cartilha do Mobral, p.14-15, sem data. Fonte: Acervo pessoal Sebastião Araújo Sobrinho

É importante compreender que a cartilha utilizada pelo Mobral foi elaborada para atender um determinado perfil de brasileiro: analfabeto e pertencente às camadas populares. Para tanto, trazia a representação da pessoa que realizava o trabalho braçal e menos remunerado,-tal como podemos observar nas imagens a seguir. Com isso, difundia-se a ideia de que aqueles profissionais seriam responsáveis por levar o país "pra frente", pois contribuíam com o seu esforço para o crescimento de uma nação "forte", além de reforçar o conceito de que todo trabalho seria digno. 


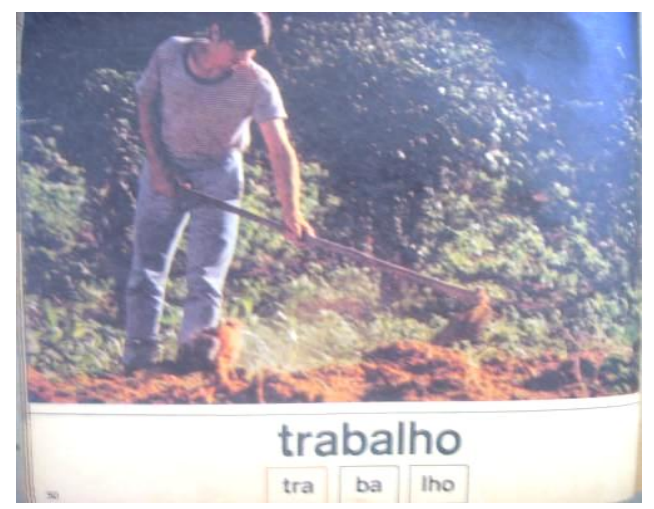

Imagem 3-Cartilha do Mobral, p.50, sem data

Fonte: Acervo pessoal Sebastião Araújo Sobrinho Sobrinho

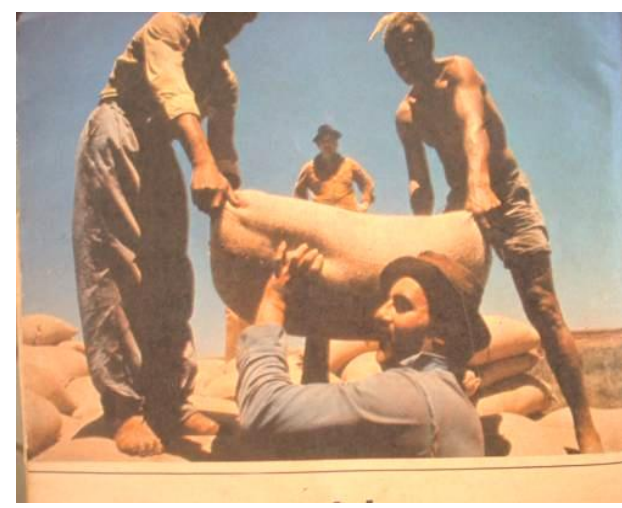

Imagem 4- Cartilha do Mobral, p.12, sem data Fonte: Acervo pessoal Sebastião Araújo

Além dos exemplos das profissões mais comuns entre a população pobre, a Cartilha do Mobral também trazia frases de estímulo à participação de "todos" na construção do "Brasil potência", tal como "O trabalho é a força de uma nação" (mesmo que mal remunerado e sob péssimas condições de realização), de modo que o trabalhador se sentisse "responsável" por esse processo.

Dentre as atividades apresentadas na cartilha do programa, havia exemplos de como os anúncios de jornais eram publicados. Nos modetós de elassifieados que a cartilha trazia, destacam-se os anúncios de empregos, os quais divulgavam a contratação de profissionais como serventes, tratoristas e outros.

Era preconizado que poderia ser construída uma sociedade onde "todos" pudessem ter uma vida "digna e fraterna", a partir de formas de convivência baseada na igualdade de oportunidades, mas, nunca na igualdade de condição social. Assim, apregoava-se que todos deveriam se comprometer e trabalhar para a construção de uma "pátria engrandecida", com homens responsáveis e solidários (ZOTTI, 2004). 
O projeto de nação propagado nesse cenário trazia a concepção de "Brasil potência", a partir de pressupostos básicos como a necessidade do oferecimento de um "mínimo de cultura para todos", o que justificava o combate ao analfabetismo por meio da implantação do Mobral, pois no contexto de uma sociedade que se urbanizava, era preciso possibilitar às amplas camadas do povo brasileiro os meios para viverem no mundo letrado (BITTAR; JÚNIOR, 2006, p. 3).

Outro aspecto recorrente no material didático do Mobral é a utilização do tema futebol, tal como podemos observar na imagem seguinte. Nessa abordagem, identifica-se a construção de uma pretensa unidade nacional, que poderia ser proporcionada a partir das comemorações dos campeonatos de futebol. Nesse contexto, tais espetáculos de distração retratavam ocasiões em que as pessoas se "uniam" em prol de algo que as identificavam. Assim, ao torcer pelo seu time, o cidadão "apoiava" a sua pátria.

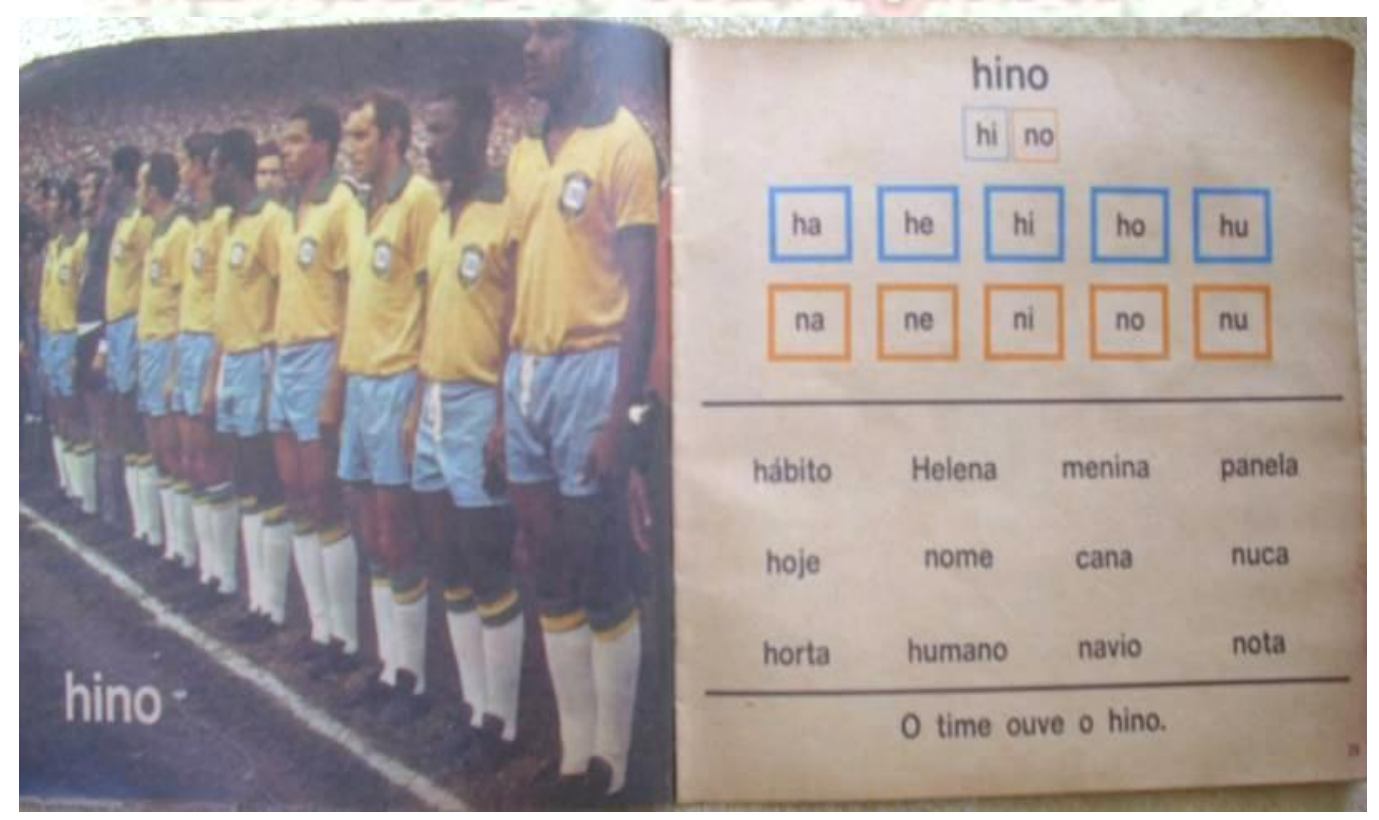

Imagem 5- Cartilha do Mobral, p.28-29 sem data. Fonte: Acervo pessoal Sebastião Araújo Sobrinho 
O esporte era entendido no contexto militar como uma possibilidade de disseminar a ideologia do novo regime e, assim, "neutralizar" as oposições ao governo. Nesse contexto, as pessoas eram estimuladas a permanecer em casa e torcer pela seleção brasileira e seus "times do coração".

\section{Os métodos e a metodologia do Mobral na zona rural de Uberlândia}

A experiência da alfabetização na fase adulta não foi apagada da memória de alguns sujeitos entrevistados, e muitos, por acreditarem na importância de se preservar a sua história, mantiveram cadernos e outros materiais utilizados no período em arquivos pessoais. A partir de tais fontes, realizamos um estudo das práticas e metodologias utilizadas no contexto das salas de alfabetização do Mobral, levantando os seguintes questionamentos: Qual a concepção de campo do material do Mobral? Nas práticas dô cotidiano, havia uma especificidade na alfabetização para o aluno do campo? Como acontecia?

Identifica-se que o Mobral mesclou alguns métodos de alfabetização na elaboração de sua proposta, em especial o método sintético.

O método sintético (composta pelos métodos alfabético, fônico
e silábico) segue a marcha que vai das partes para o todo, e
implicava na memorização e repetição de exercícios.
Privilegia-se a decoração de sinais gráficos e as
correspondências fonográficas. De maneira geral, parece que a
escolha por apenas um caminho para sistematização das
relações fonema-grafema a letra, o fonema ou a sílaba, é que
diferencia o tratamento em torno das correspondências
fonográficas (FRADE, 2007, p. 22).

Também é importante destacar que, apesar de ter considerado o método Paulo Freire como "subversivo" naquele período, o programa incorporou alguns de seus pressupostos, tal como a utilização do Cartaz Gerador, com o estudo da palavra geradora e a decomposição silábica da 
palavra. Desse modo, entende-se que o Mobral se apropriou de algumas metodologias da proposta do autor, contudo não numa perspectiva conscientizadora, como era a intenção de Paulo Freire, mas com intuito de conservar a ordem vigente.

Nessa perspectiva, Brandão (1981) esclarece que a palavra geradora na proposta de Paulo Freire pautava-se no levantamento do universo vocabular da população jovem e adulta que seria alfabetizada. Para tanto, era necessário utilizar palavras, frases, ditos, provérbios e canções que faziam parte do cotidiano do educando. Tratava-se de um processo de pesquisa que, por sua vez, deveria ser um ato criativo, uma descoberta coletiva da vida por meio da fala Assim, a descoberta do mundo por intermédio da palavra não deveria servir apenas para a simples alfabetização por meio de um conjunto de palavras e frases. Esse processo deveria servir também para criar momentos de novas descobertas.

Ao analisar o conteúdo da Cartilha do Mobral, identificou-se que a metodologia utilizada no programa também importou algumas características utilizadas pela cartilha Caminho Suave. Podemos observar algumas semelhanças entre as cartilhas, em especial, chama-nos a atenção a similaridade na estrutura gráfica dos materiais, conforme apresentamos abaixo: 


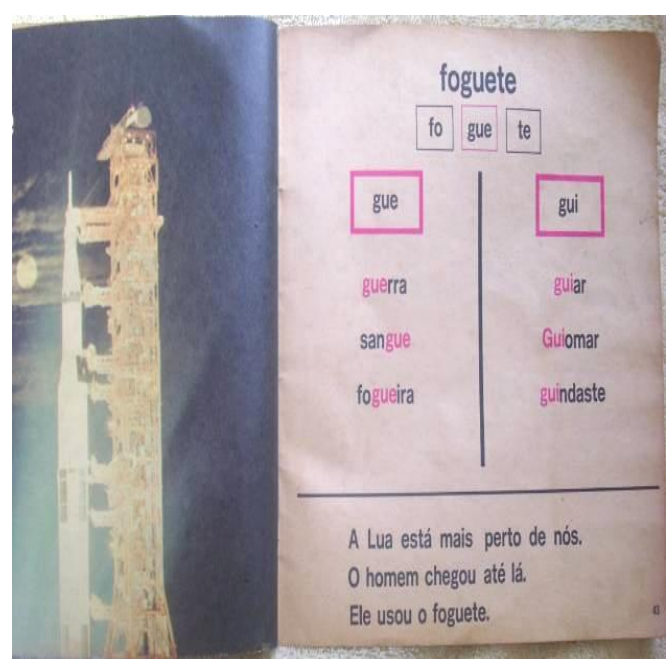

Imagem 6- Cartilha do Mobral p. 42-43, sem data

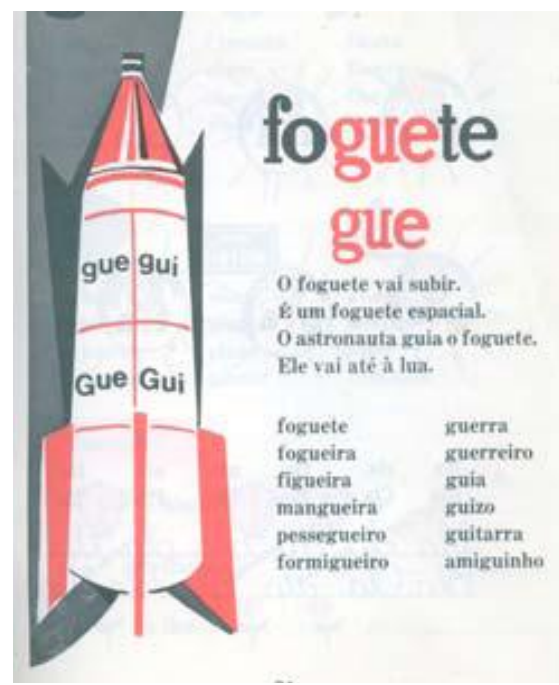

Imagem 7- cartilha Caminho Suave, 1981

Nota-se a semelhança na estrutura e método de alfabetização das duas cartilhas, sobretudo no que concerne a ênfase às habilidades visuais. Nas duas cartilhas, constata-se a utilização do método sintético (silábico.), que partia das partes para o todo, isto é, da síntese para a análise, a partir do ensino da leitura baseado na associação de letras aos seus nomes e à imagem que representasse a letra a ser estudada. Nesse processo, após reunir as letras em sílabas, passava-se ao conhecimento das "famílias_silábicas", posteriormente, ensinava-se a ler palavras formadas com as mesmas sílabas e letras e, por fim, aprendiam-se frases isoladas (ARAÚJO; SANTOS 2008, p.8-9).

Evidencia-se que a cartilha "Caminho Suave", na qual o Mobral se baseou para elaboração de parte de seu material didático, adotava uma metodologia que pode ser considerada inadequada às demandas do público adulto, uma vez que a primeira cartilha foi criada para alfabetizar crianças. Portanto, utilizava recursos, metodologias e linguagem direcionados ao público infantil. Para adaptação à alfabetização dos adultos, identifica-se 
apenas que o Mobral não utilizou desenhos, como era comum na cartilha "Caminho Suave", e sim fotos de situações "reais".

No caso dos alunos que residiam no campo, o conteúdo da Cartilha do Mobral não se aproximava de forma significativa da sua realidade, seja pela ênfase ao contexto urbano ou na utilização de imagens que não tinham nenhuma relação com a rotina da vida rural, como o exemplo da figura do foguete apresentada anteriormente.

$\mathrm{Na}$ análise dos métodos e das metodologias utilizadas no cotidiano das aulas do Mobral na zona rural de Uberlândia, constatou-se que, como as professoras entrevistadas não tiveram formação didática para ensinar pessoas adultas, acabavam por reproduzir as práticas que realizavam com as crianças, pois todas já atuavam no ensino das séries iniciais do ensino fundamental.

A professora que atuou no programa no distrito do Cruzeiro dos Peixotos revela que no Mobral foi a primeira vez que "tentou" alfabetizar adultos. Desse modo, ressalta que teve insegurança e muito medo da desistência, pois "os alunos eram senhores e senhoras que tinham dificuldade até de pegar no lápis, eram trabalhadores".

Como forma de facilitar o processo de alfabetização dessas_pessoas, alguns procedimentos pedagógicos, muito utilizados com a alfabetização de crianças, foram introduzidos na prática dessa professora. "Entendíamos que através do desenho eles iriam aprender". Esses procedimentos eram inseridos como alternativas "não oficiais", como forma de introduzir a sua metodologia de trabalho já realizado com as salas de alfabetização de crianças.

Nesse processo, as professoras atuantes no Mobral da zona rural de Uberlândia também elaboravam e utilizavam outras atividades na tentativa de alfabetizar seus alunos adultos. Por exemplo, nos cadernos de ex-alunos foram identificadas atividade mimeografadas. 
Contudo, nos relatos, uma das professoras entrevistadas avalia que não contribuiu para uma alfabetização efetiva dos adultos. Lembra que não concordava com a estrutura do material do programa e, por esse motivo, não seguia a sequência das atividades preestabelecidas. Preferia elaborar e desenvolver atividades alternativas, tais como as que aplicavam para as crianças, pois acreditava que assim obteria melhores resultados.

A professora avalia que, em função de alguns fatores, não foi possível alcançar resultados satisfatórios na sua experiência com o Mobral. Assim, devido ao pouco tempo que tinham para alfabetizar as turmas, além das dificuldades que os alunos adultos apresentavam (pelo histórico de exclusão do ensino formal), conclui que a campanha foi um fracasso.

Diante disso, dentre as lacunas que o Mobral apresentou, enfatiza-se a falta de formação adequada das professoras para lidar com os alunos adultos. Muito embora o programa contasse com o empenho dessas professoras, a falta de alinhamento dos seus objetivos com os interesses da população rural acabava por reforçar o sentimento de fracasso na maior parte dos alunos, que abandonavam as aulas e também, em parte, nos professores.

Mesmo que essas professoras tivessem vasta experiência em sala de aula, o seu foco era a alfabetização de crianças. E, como não tiveram uma orientação adequada para alfabetizar aquele "novo público", acabaram por introduzir práticas destinadas às crianças. Esse processo dificultava a alfabetização dos adultos, pois eles necessitavam de outros caminhos pedagógicos para aprender.

[...] muito difícil, eles tinham o tempo deles, o jeito deles, tudo já tá definido neles, você não tem o que moldar como uma criança que você vai e faz. Agora, entrar naquele mundo dele era muito difícil. Eu, por exemplo, não tive sucesso no Mobral. Eu trabalhei 12 anos com alfabetização de crianças, e o sucesso era extraordinário (SANTOS, 2008). 
Na concepção dessa professora: "parece que a escola assustou eles, uma pessoa que nunca tinha ido à escola era difícil." A ansiedade de aprender rápido a ler e a escrever também era um aspecto que a professora considerava negativo nesse processo de ensino-aprendizagem, uma vez que “eles achavam que iriam aprender [...] rápido, eles não tinham aquela paciência de ficar na escola. Eles não tinham noção do que era ler e escrever, se passasse tarefa eles não davam conta de fazer aquilo".

No relato da professora, evidencia-se que, no ensino dos adultos, as práticas do cotidiano com as crianças eram reproduzidas nas salas do Mobral que, por sua vez, era motivo de constrangimento para esses trabalhadores. $\mathrm{Na}$ fala que destaca que "tudo tem que ser aprendido" pode revelar uma verdadeira empreitada civilizatória ainda em fins do século XX.

Quanto ao conteúdo do material didático que o Mobral apresentava, a professora avalia que, apesar de não considerá-lo de boa qualidade, "era fácil de trabalhar", pois "não tinha muito conteúdo, era mais atividade de descobrir o código, de aprender o código, uma palavra, outra palavra". A professora revela que os exercícios propostos no material didático do programa não demandavam "análise do aluno ou de muito trabalho mental para entender, era fácil." Nesse sentido, em sua reflexão sobre os resultados do programa, relata que, também em função da pouca qualidade da cartilha, o Mobral não teve êxito. Assim, os conteúdos desse material "não tinha nada que mexia com a consciência das pessoas".

Diante do exposto, explicita-se que o Mobral oferecia cursos aligeirados para a alfabetização da população jovem e adulta campesina. Esse público, por sua vez, quando conseguia concluir os cinco meses do curso, não tinha oportunidade de dar continuidade aos estudos nas salas do programa localizadas na zona rural, pois ao terminar o período previsto para a alfabetização, eram encerradas as turmas e começavam outras, e os alunos não podiam se inscrever novamente. 


\section{Considerações finais}

Entretanto, as salas do Mobral, não proporcionaram mais que o aprendizado da codificação e decodificação da língua escrita. E conforme apontam alguns relatos das professoras, esse aprendizado era suficiente e de grande valia para os alunos, pois esses desejavam, principalmente, aprender escrever o nome para não sofrer constrangimentos.

Acreditamos que o esforço dos ex-alunos do Mobral da zona rural do município de Uberlândia deve ser valorizado, por outro lado, enfatizamos o longo período de abandono da escola rural. Nesse sentido, priorizavam-se ações compensatórias, não políticas públicas efetivas pảa atender as demandas daquela população.

Nesse sentido, constata-se que os cursos aligeirados do Mobral não possibilitavam aos alunos se alfabetizarem de fato, por outro lades eram impedidos de se inscreverem novamente nas salas de Alfabetização Funcional, pois cada pessoa podia se matricular apenas uma vez no Mobral. Diante disso, verifica-se que esse processo contribuiu para elevar as estatísticas governamentais, contudo, não mudou a realidade de milhăres de brasileiros que, mesmo tendo passado pela experiência do Mobral, permaneceram não alfabetizados.

Diante disso, ressaltamos que a efetiva alfabetização daqueles jovens e adultos não se concretizou em função de inúmeros fatores, seja pelo material inadequado àquela faixa etária ou pela falta de preparo das professoras para alfabetização dos trabalhadores jovens e adultos do campo, dentre outros.

\section{Referencial bibliográfico}

ARAÚJO, Gustavo Cunha de; SANTOS, Sônia Maria dos. A Cartilha Caminho Suave: História, Memória e Iconografia. Fênix - Revista de 
História e Estudos Culturais. Vol. 5. Ano V no 2. Abril/ Maio/ Junho de 2008.

BEZERRA NETO, Luiz. Avanços e retrocessos na educação rural no Brasil. Tese de doutorado. Universidade Federal de Campinas/SP, 2003.

BITTAR, Marisa; JÚNIOR, Amarilio Ferreira. Jarbas Passarinho, Ideologia Tecnocrática e Ditadura Militar. Revista HISTEDBR On-line, Campinas/SP, n.23, p. 3 -25, set. 2006 - ISSN: 1676-2584. Disponível em: <http://www.histedbr.fae.unicamp.br/art01_23.pdf> Acesso em 2 ago. 2010.

BRANDÃO, Carlos Rodrigues. O que é Método Paulo Freire. Editora Basiliense, $4^{\text {a }}$ Edição. São Paulo/SP, 1981.

BRASIL: Instituto Brasileiro de Geografia e Estatística (IBGE). Censo Demográfico 1940-2000. Rio de Janeiro: IBGE, 1950-2001. Dádos extraídos de: Estatísticas do século XX. Rio de Janeiro/RJ: IBGE, 2007. $\begin{array}{llll}\text {.Diversas tabelas. } & \text { Disponível }\end{array}$ <http://www.ibge.gov.br/seculoxx/arquivos xls/palavra chave/educacao/in dicadores_de_ensino.shtm> Acesso em 20 nov. 2010.

CUNHA, Luiz A.; GÓES, Moacir de. O Golpe na Educação. Rio de Janeiro: Zahar, 2002.

FERNANDES, Sheila Maria Pereira. Política para Educação de Jovens e Adultos - Os desafios para implementação e a manutenção da PMA no município de Uberlândia-MG (Anos 1980 - 2000). Dissertação de mestrado. Universidade Federal de Uberlândia/MG, 2002.

FRADE, Isabel Cristina Alves da Silva. Métodos de alfabetização, métodos de ensino e conteúdos da alfabetização: perspectivas históricas e desafios atuais. Santa Maria/RS, v. 32 - n. 01, p. 21-40, 2007.

FREITAS, Marcos Cezar de. História Social da Educação no Brasil. São Paulo/SP. Cortez, 2009.

FUGIKAWA, Cláudia Sueli Litz. et al. Educação Física. -Secretaria de Estado da Educação Curitiba/PR.2 2a Edição, 2006.

NUNES, Nataly; REZENDE, Maria José de. O ensino de Educação Moral e Cívica durante a ditadura militar. In:do III SIMPÓSIO LUTAS SOCIAIS DA AMÉRIA LATINA. Londrina/PR. Anais... Grupo de Estudos de Política da América Latina - GEPAL. 2008. Disponível em: <http//UEL.br/grupo.pesquisa/gepal/anais-iii.htm>. Acesso em 09 jul. 2010. 
PAIVA, Vanilda. Educação Popular e Educação de Adultos. São Paulo/SP, 1987

SKIDMORE, Thomas E. Brasil: de Castelo a Tancredo, 1964-1985. Rio de Janeiro/RJ. Paz e Terra, 1988.

VIEIRA, Maria Clarisse. Políticas de Educação de Jovens e Adultos no Brasil: experiências e desafios no município de Uberlândia/ MG (anos 80 e 90). Dissertação de mestrado, Universidade Federal de Uberlândia, 2000.

ZOTTI, Solange. As configurações do currículo oficial no Brasil no contexto da Ditadura Militar. In: III CONGRESSO DE HISTÓRIA DA EDUCAÇÃO: EDUCAÇÃO ESCOLAR EM PERSPECTIVA HISTÓRICA. Curitiba/PR. Anais... 2004. Disponível em: <www.sbhe.org.br/novo/congresso/cbhe3/documentos/indivd/Eixo3/213.pdf > Acesso em: 21/07/2010.

\section{Fontes impressas:}

BRANCA A. Lima Cartilha Caminho Suave: Alfabetização Pela Imagem, 84 Edição, 1981.

CARTILHA DO MOBRAL, sem data.

\section{Fontes orais:}

SANTOS, Edna Ferreira dos. Ex professora do Mobral/Cruzeiros dos Peixotos. Entrevista concedida a Letícia Borges de Oliveira em 16 de novembro de 2008 


\section{AUTORES}

Letícia Borges de Oliveira

Universidade Federal de Uberlândia

Contato: leticiaborgesufu@yahoo.com.br

Sauloéber Társio de Souza

Universidade Federal de Uberlândia

Contato: sauloeber@gmail.com

Artigo recebido em fevereiro de 2012.

Aceito para publicação em abril de 2012.

\section{Como citar este texto:}

OLIVEIRA, L. B.; SOUZA, S. T.. A alfabetização no Mobrat, métodos e materiais-didáticos (Uberlândia/MG, 1970-1985). Revista Acolhendo a alfabetização nos países de língua portuguesa, Brasil, São Paulo, volume 1, $\mathrm{n}^{\circ}$. 13, pp. $11 \quad$ - 37, Set. 2012. Disponível em: $<$ http://www.acoalfaplp.net>. 